\title{
Why All Professional Scientists Should Teach
}

\author{
Kass L* \\ School of Biology \& Ecology, University of Maine, USA
}

*Corresponding author: Leonard Kass, School of Biology and Ecology, University of

Maine, Orono, ME 04469 USA, Email: leonard.kass@maine.edu

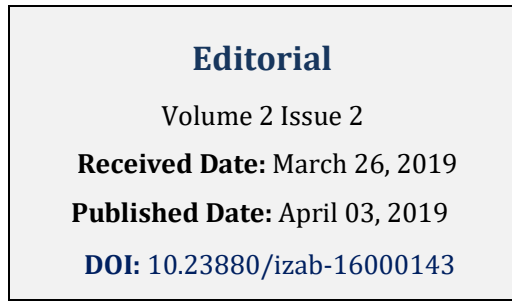

\section{Editorial}

Should researchers teach or not? George Bernard Shaw once wrote "He who can does; he who cannot, teaches [1]." I was first introduced to that quip in the formulative years of my early Teens. Later, in personal experiences as a professional scientist, I observed that many science faculty members at great universities were hired with minimal, if any, teaching experience or interest. Research prowess, alone, trumped all other qualifications. At most top universities, the teaching of undergraduates was an assigned duty that came with the territory, an unrewarded obligation and not a vocation. A young research scientist who preferred teaching would risk tenure and employment. In contrast, Robert Menzies, in the Australian House of Representatives, stated "It appears, therefore, that of all secular professions, teaching is the most profoundly important [2]." Menzies later enjoyed an extraordinarily long and successful career as Prime Minister of Australia (1939-1941; 1949 1966). As professional scientists and researchers, what are we to do with these opposing aspirations and realities? The thesis expressed here is that teaching science is not only compatible with conducting scientific research, it is an imperative for the profession of science to thrive.

The profession of science gains when trained and experienced researchers teach. Jongmans and collaborators [3] conducted studies on the way teachers with different professional backgrounds teach. Their results showed important pedagogical differences between those who teach topics from a book, versus those who teach after having actively engaged in research at a deep professional level. Their research revealed that teachers with greater depth and experience in their field of study showed greater willingness to implement innovations, less self-concern or detailed task-concern, while demonstrating greater collaboration among other teachers. Students gain first-hand and realistic perspectives on the findings and practice of science when those who actually conduct it do the teaching. One complaint from students learning science is that the subject can be dry. When scientists choose research as their profession, they derive joy from conducting and sharing their work. Who better to impart that enthusiasm and excitement of the "hunt" for exceptional students than the professional scientists who engage in research frequently. Unlike some other disciplines, science is a specialized and highly dynamic process, not a collection of solidified facts contained in a book. Teaching science as process is best done by experienced researchers, whereas disseminating facts from a book could be done by others. Having the best teachers for the job at hand may be most critical during formulative stages in a student's education. Charles H Mayo (1865-1939), one of the founders of the internationally renowned Mayo Clinic, once said, "The safest thing for a patient is to be in the hands of a man involved in teaching medicine. In order to be a teacher of medicine the doctor must always be a student [4]." Mayo has been described not only as an inspirational teacher, but also as an extremely gifted surgeon [5]. The same can be applied to the teaching of science by a researcher. By teaching, the research scientist places the student's education in the safest hands and becomes a student alongside them as well.

There are numerous personal benefits gained by the researcher who teaches science. Science is a multiplegenerational enterprise that has been and will be continued for generations of scientists. What an individual researcher accomplishes personally in their professional lifetime pales in comparison to what will be accomplished multi-generationally across the entire scientific community. Teaching science allows the 


\section{International Journal of Zoology and Animal Biology}

professional the honor of carrying the illuminating torch forward, while handing it to their students in that subsequent generation. Richard Feynman, surely one of the greatest theoretical scientists of our age, said the following about his own teaching [6].

"I don't believe I can really do without teaching. The reason is, I have to have something so that when I don't have any ideas and I'm not getting anywhere I can say to myself, 'At least I'm living; at least I'm doing something; I am making some contribution' -- it's just psychological.

In any thinking process there are moments when everything is going good and you've got wonderful ideas. Teaching is an interruption, and so it's the greatest pain in the neck in the world. And then there are the longer period of time when not much is coming to you. You're not getting any ideas, and if you're doing nothing at all, it drives you nuts! You can't even say 'I'm teaching my class.'

So, I find that teaching and the students keep life going, and I would never accept any position in which somebody has invented a happy situation for me where I don't have to teach. Never."

I find it interesting that Feynman, known as a great teacher, intuitively incorporated the teaching styles referred to above by Jongmans and collaborators: Willingness to innovate, with little or no concern for self or detailed task-involvement while involving other professionals in his teaching. We would do well adapt his methods and techniques while engaging students of science. Genderisms, racisms, nationalisms, religion-isms, along with a host of other -isms still afflict humanity today. The teaching of science, particularly biology, is the best inoculation against those debilitating and lethal memes and mental pathologies within societies. The excitement and joy of conducting scientific research is conveyed through teaching science. Improving the world's humanity by the teaching of biology is worthy of the very best among us.

Acknowledgement: The author thanks Janice L. Pelletier, MD., for reading this piece and for providing her thoughtful suggestions.

\section{References}

1. Shaw B (1903) Maxims for Revolutionists. Man and Superman.

2. Menzies R (1945) Records of the Australian House of Representatives.

3. Jongmans CT, Sleegers PJC, De Jong FPCM, Biemans HJA (1998) Teachers' professional orientation and their concerns. Teacher Development 2(3): 465-479.

4. Mayo C (2019) Science Quotes by Charles Mayo.

5. Charles Horace Mayo (2019).

6. Richard Feynman, Ralph Leighton (1985) Surely You're Joking, Mr. Feynman!: Adventures of a Curious Character. In: Edward Hutchings, (Ed.), Blackstone Audiobooks unabridged audio cassette, W W Norton, USA, pp: 400 pages. 